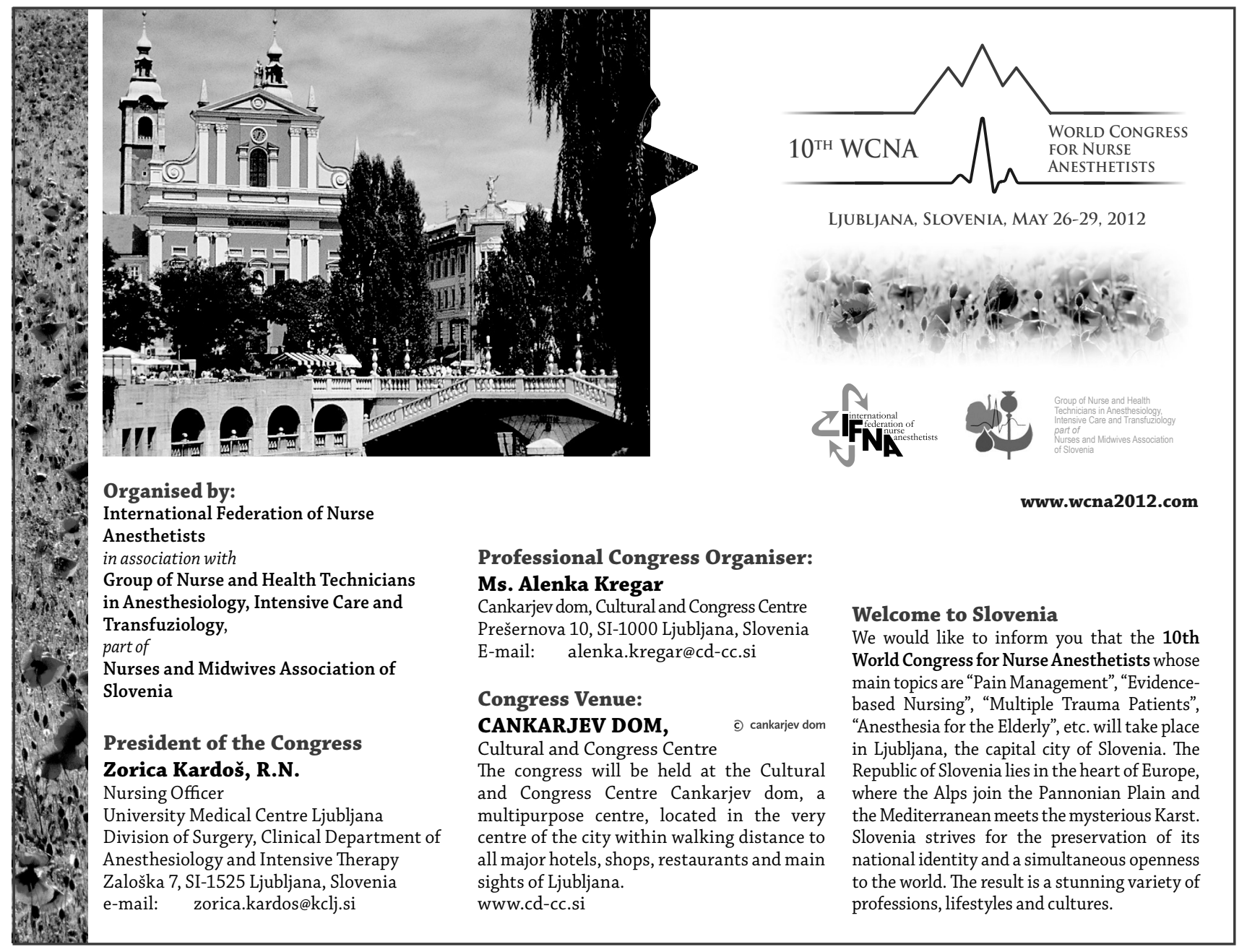


https://doi.org/10.1017/S1742645612000204 Published online by Cambridge University Press 


\section{BRITISH JOURNAL OF}

\section{ANAESTHETIC \& RECOVERY NURSING}

\section{CONTENTS}

FROM THE CHAIRMAN

- 25 years of BARNA

Natalie Quine

\section{CONFERENCE REPORT}

- American Society of Peri-Anaesthesia Nurses Conference 2011

Natalie Quine

- 25th Annual Conference, Annual General Meeting and Exhibition, Birmingham

Jessica Inch

EDITORIAL

\section{- New Faces}

Lee Lui, Lucie Llewellyn

\section{ORIGINAL ARTICLES}

- A Qualitative Study: Why Prolonged Stay in the Recovery Room?

Sharifa B. Lalani, Fauzia Ali, Zeenatkhanu Kanji,

Salma Jaffer, Mohammed Ali
- Thoracotomy Paraplegia: A Case Report from the PACU

Tzu H. Huang

EDUCATION

- The Thoughts of a Junior Nurse Dean Butler

- Effective Learning in the Practice Setting Nicholas Gladstone

INTERVIEW

- Meet the Team Jacqui Bishop 